\title{
The LOTRED Approach - A First Step Towards a "Paleoreanalysis" for Europe
}

Heinz WANNER AND JÜrg LUTERbacher

Institute of Geography and NCCR Climate, CH-3012 Bern, Switzerland; Heinz.Wanner@giub.unibe.ch, Juerg.Luterbacher@giub.unibe.ch

Temperature is the classical state variable, which is closest to the energy state of the climate system. Therefore, a large number of paleoclimate studies compare either single time series or spatiotemporal reconstructions of surface air temperature with relevant forcing factors (e.g. Mann et al. 1998). In order to analyze and understand the dynamical processes responsible for interannual to centennial scale climate variability over particular regions however, additional important state variables such as air pressure, wind, precipitation and sea surface temperature (SST) must be considered and separately reconstructed. The basic idea of the Long Term REconstruction and Diagnostics (LOTRED) approach is to combine long-term data sets in order to provide a "paleoreanalysis," which allows the diagnosis of important processes. LOTRED also aims to relate trends and variations in atmospheric circulation over the last centuries to European surface climate (temperature and precipitation) variability, and its extremes, as well as North Atlantic sea surface temperature patterns.

\section{Statistical reconstructions of large scale climate fields}

The LOTRED approach is based on the assumption that the four basic state variables, sea level pressure (SLP), temperature, precipitation and SST, can be reliably and independently (no common predictor data for each variable) reconstructed with a sufficient spatial $\left(0.5^{\circ}\right.$ - $5^{\circ}$ ) and temporal (seasonal to monthly) resolution. In Europe, thanks to a large number of long instrumental climate observations, much documentary evidence, and information from natural archives, a detailed study of climate evolution over the last few centuries is possible. Climate information from these different sources, with their complementary strengths, are used

Table 1: Time-series (predictors) available for the European precipitation, temperature, SLP and Atlantic SST reconstructions for winter 1739/1740. (I) stands for indexed data (estimated from high resolution documentary evidence), the remaining series are based on instrumental measurements: Note that the indexed temperature and rainfall indices mostly represent the climatic conditions over a broader geographical area and do not refer to a single station. For more details and sources see Luterbacher et al. (2002).

\begin{tabular}{|llll|}
\hline Precipitation & Temperature & SLP & Atlantic SSTs \\
\hline Podehole (UK) & Central England (CET) & Uppsala (Sweden) & 69Tree-rings \\
Hoofdoorp (NL) & De Bilt (NL) & Padova (Italy) & series from \\
Kew (UK) & Berlin (Germany) & Northe \\
Zürich (CH) & Uppsala (Sweden) & America, \\
Southern Jordan & Tornio (Finland) & Europa and \\
(Tree ring based) & (I) Swiss Middleland (CH) & \\
(I) Swiss Middleland (CH) & (I) Southern Germany (D) & \\
(I) Southern Germany (D) & (I) Hungary & \\
(I) Hungary & (I) Czech Republic & \\
(I) Seville (Spain) & (I) Western Baltic Sea-Ice & \\
(I) Murcia (Spain) & & & \\
(I) Barcelona (Spain) & & & \\
\hline
\end{tabular}

to estimate large-scale climate variability over the last few centuries. One common method uses a multivariate calibration of the available data against instrumental records. A given large-scale climate variable is calibrated simultaneously against all information in the predictor network. Thus, local relationships between instrumental station time series, documentary and natural proxies and the predictor field are not necessary. The statistical relationship (commonly determined through a principal component-multivariate regression) is usually developed over a calibration period within the 20th century and verified using independent, instrumental observations or through cross-validation exercises. This is done in order to gain insight into how well the derived statistical relations, based on the numbers of predictors during the calibration period, can estimate the climate state of a variable in another independent period. The quality of the reconstructions within the $20^{\text {th }}$ century is usually assessed by a number of statistical measures. To obtain the most reliable recent variability, it is customary practice to use all available data from the $20^{\text {th }}$ century to establishing transfer functions used to derive the reconstructions.

\section{The Extreme Winter 1739/40:}

\section{An Example of LOTRED}

To demonstrate the LOTRED approach, we selected the exceptionally cold European winter of 1739/1740. This example illustrates both the potential and the limitations of independently reconstructing highly resolved temperature, precipitation, pressure and SST fields, based on a combination of a few early instrumental, natural and documentary proxy time series. Table 1 shows the available time series, which were used for the independent reconstructions of the winter 1740 climate fields. For land temperature and precipitation, we used the New et al. (2000) data $\left(0.5^{\circ} \times 0.5^{\circ}\right.$ resolution) for calibration. In the case of the SLP field, we employed data from Trenberth and Paolino (1980) $\left(5^{\circ} \times 5^{\circ}\right.$ resolution). For the Atlantic SST, data were obtained from the analyzed global sea surface temperature (SST) anomalies (Kaplan et al., 1998) $\left(5^{\circ} \times 5^{\circ}\right.$ resolution). Temperature, precipitation and SLP were calibrated with the available predictor sets (Table 1) over the period 1931-1995, and SSTs were fitted over 1856-1940.

\section{Quality assessment of the reconstructions}

The skill of each of the statistical models was assessed over 1901- 


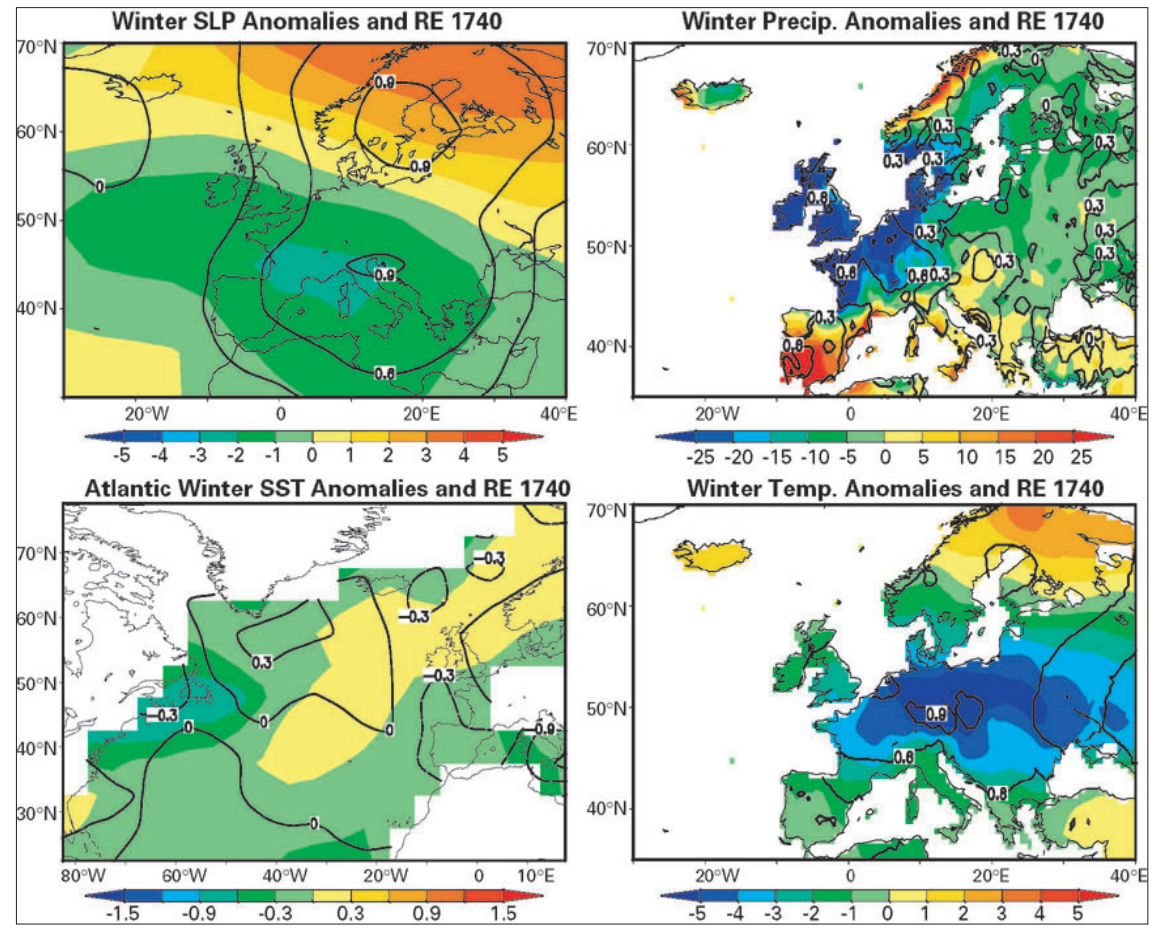

Fig. 1: Reconstructed anomaly patterns for winter (DJF) 1739/40, SLP (top left), European land precipitation (top right), European land temperature (bottom right) and North Atlantic SSTs (bottom left). All fields are plotted with reference to the winter average from 1951-1980. The anomalies for temperature and SST are in ${ }^{\circ} \mathrm{C}$, for precipitation in $\mathrm{mm}$ and for SP in $\mathrm{hPa}$. Due to the spatial resolution of the SST data, coloured parts of the continent should be neglected. The contour lines in each plot represent the model performance (Reduction of Error, RE) for the reconstructed fields plotted against the time period for which the given statistical model (verification period 1901-1930 for SLP, temperature and precipitation, respectively and 1941-1980 in the case of the SSTs) was used. Areas with $R E>0$ are indicated by solid lines, areas with $R E<0$ are indicated by dashed lines.

1930 (temperature, precipitation and SLP) and 1941-1980 for SST by the Reduction of Error (RE) statistic. The range of $R E$ is $(-œ,+1)$ with a zero value representing the skill of climatology and increasingly positive values representing increased regression skill. $A R E$ of +1 indicates a perfect reconstruction, whereas a RE of -1 is a random guess. The contour lines in Figure 1 thus give an indication of how well the climate fields can be reconstructed based on the available predictor data in an independent period. After the assessment, we recalibrated over the period 1901-1995 (temperature, precipitation and SLP) and 1856-1980 (Atlantic SSTs) in order to derive the winter $1739 / 1740$ fields. For a detailed mathematical treatment of the reconstruction method see Luterbacher et al. (2002).

\section{The winter 1739/40: dynamical aspects}

Figure 1 presents the reconstructed anomalies (with regard to the 19511980 reference period) of SLP, precipitation, temperature and Atlantic SSTs together with the RE values. The reconstructed winter SLP (top left) indicates higher pressure north of $60^{\circ} \mathrm{N}$ with a maximum anomaly of $4 \mathrm{hPa}$ over northern Scandinavia. Lower pressure covers the area to the south with the largest departures occuring over southern France and Italy. The model performance presented by the contour lines indicates positive $R E$ values over the entire grid with maximum values close to the predictor regions (Padova and Uppsala) and a gradual decrease towards the periphery of the grid. Thus despite having only two station pressure series, meaningful SLP reconstructions can be achieved over continental Europe, though this skill does not extend over the Atlantic ocean west of $20^{\circ} \mathrm{W}$.

It is well known that the largescale atmospheric circulation determines, to a large extent, regional precipitation and temperature anomalies. Thus, advective processes are a crucial factor controlling regional climate changes. According to the reconstructed SLP anomaly pattern, one would expect anomalously dry air to be advected from an easterly direction (Russia) towards continental Europe. In fact, the precipitation anomaly chart (Fig. 1, upper right) clearly indicates a gradual reduction in winter precipitation from east to west. The driest regions are found over north-western Europe and the UK. Wetter conditions are prevalent over the Mediterranean areas, especially over the Iberian Peninsula, which would expected due to a negative NAO situation with more cyclones tracking towards the south. However, not all regional details are due to forcing from the large scale, winter season average circulation. For instance, it is not clear why the western part of Scandinavia received above normal precipitation despite strong positive pressure anomalies. A glance at the higher resolution reconstructed monthly winter conditions reveals that the December 1739 and February 1740 flow over this area was, unlike in the seasonal mean recostruction, from a southwesterly direction. Thus, the effect of these two months might be responsible for the above normal seasonal rainfall anomalies. Generally, areas with a strong intra-winter circulation variability might be expected to have divergent average temperature and precipitation patterns which are not easy to interpret. The quality of the precipitation reconstructions based on 11 rainfall time series is lower and mostly does not reach an RE value of 0.7. Areas with RE values lower than 0.3 should be considered with caution.

The anomalous easterly flow indicated by the SLP anomaly chart is consistent with a large area of Europe showing cold winter temperatures (Fig. 1, lower right). Central and eastern Europe especially, experienced a winter with temperatures up to $5^{\circ} \mathrm{C}$ lower than average. Warmer than normal conditions were only prevalent over Iceland, northern Scandinavia and Russia. This might be due to south-westerly flow over these areas in December 1739 and February 1740. In fact, the station Tornio at the border between Sweden and Finland, also used for the reconstruction, clearly indicates milder conditions compared to the 1951-1980 mean. The RE values for large areas are high and reach up to 0.9 . Thus, with only 10 temperature time series were used, there are large areas with meaningful reconstruction 
skill. In addition, independent climate information sources from various areas, which are not included in the reconstructions, are consistent with the reconstructed temperature and precipitation patterns.

As expected, the reconstruction of the Atlantic SSTs, based on remote tree-ring data from America, Europe and Morocco, reveals only small areas with some reconstruction skill (positive RE-values). These results indicate that the reconstructed SSTs should not be over-interpreted and that more accurate predictors for the reconstructions of this variable have to be found.

\section{Conclusions and outlook}

Reconstruction of European climatic variables over the last few centuries is made possible by the specific combination of data from documentary sources, natural archives and early instrumental measurements. Without documentary data, a satisfactory spatial resolution cannot be achieved for periods when instrumental data are lacking. Thus, they provide an important base for the reconstruction of processes responsible for the strong climate fluctuations in Europe during the second half of the Little Ice Age. We took the first step of developing temporally and spatially highly resolved histories for several climate variables in the past. Such histories are required in order to facilitate the search for an unambiguous 'fingerprint' of recent climate response to increasing greenhouse gas emissions. We therefore hope that our preliminary 'paleorenalysis' results, alongside long-term hindcast runs of coupled general circulation models, will provide a better understanding of the underlying processes associated with both natural and anthropogenic climate change. A question that merits further discussion is whether or not it would make sense to start an initiative to produce a more comprehensive paleoreanalysis product based on further European, or even global, multi-proxy data.

\section{ACKNOWLedgements}

The authors wish to thank Rudolf Brázdil and Mariano Barriendos for providing temperature and precipitation indices for the Czech Republic and Spain. The whole ADVICE, IMROVE, WASA and ALOCLIM projects consortium is acknowledged for the use of their homogenised data.
We wish to express our thank also to Ed Cook and Mary Glueck for providing their tree-ring data and Alexey Kaplan for the use of SST data. The gridded temperature and precipitation data has been supplied by the Climate Impacts LINK Project (UK Department of the Environment Contract EPG 1/1/16) on behalf of the Climatic Research Unit, University of East Anglia. Elena Xoplaki is acknowledged for drawing the figure.

\section{REFERENCES}

Kaplan, A., Cane, M., Kushnir, Y., Clement, A., Blumenthal, M. and Rajogopalan, B., 1998: Analyses of global sea surface temperature 1856-1991, Journal Geophysical Research, 103, 18567-18589. Luterbacher, J., Xoplaki, E., Dietrich, D., Rickli, R., Jacobeit, J., Beck, C., Gyalistras, D., Schmutz, C. and Wanner, H., 2002: Reconstruction of Sea Level Pressure fields over the Eastern North Atlantic and Europe back to 1500, Climate Dynamics, 18, 545-561.

Mann, M.E., Bradley, R.S. and Hughes, M.K., 1998 Global-scale temperature patterns and climate forcing over the past six centuries, Nature, 392 779-787.

New, M., Hulme, M. and Jones, P.D., 2000: Representing Twentieth-Century space-time climate variability. Part II: Development of 1901-1996 monthly grids of terrestrial surface climate, Journal of Climate, 13, 2217-2238.

Trenberth, K. and Paolino, D.A., 1980: The Northern Hemisphere sea-level pressure data set: trends, errors and discontinuities, Monthly Weather Review, 108, 855-872

\title{
The Potential of Archival Sources for Reconstructing Climate and Climate-Related Processes in Latin America
}

\author{
S.e. Metcalfe ${ }^{1}$, M.del R. Prieto ${ }^{2}$, G.H. Endfield ${ }^{3}$, S.J. Davies ${ }^{4}$, S.L. 0'Hara ${ }^{2}$ \\ ${ }_{1}^{1}$ Geography, School of Earth, Environmental and Geographical Sciences, University of Edinburgh EH8 9XP, UK; sem@ossian.geo.ed.ac.uk \\ 2Unidad de Historia Ambiental, Instituto Argentino de Nivologia, Glaciologia y Ciencias Ambientales, 5500 Mendoza, Argentina; \\ mrprieto@lab.cricyt.edu.ar, ohara@geography.nottingham.ac.uk \\ 3 School of Geography, University of Nottingham, Nottingham NG7 2RD, UK; Georgina.Endfield@nottingham.ac.uk \\ ${ }^{4}$ Institute of Geography and Earth Science, University of Wales, Aberystwyth SY23 3DB, UK; sjd@aber.ac.uk
}

Following the conquest of Mexico and large portions of Central and South America in the $16^{\text {th }}$ century, the Spanish Colonial administration began compiling documents on population, settlements, landscapes and economic resources. Combined with the collections of judicial documents including law suits and land grants, the various pictographic, ethnohistorical sources dating back to the pre- and early post-Conquest period and the scientific reports and travelogues of visitors, this archival legacy represents an incredibly rich media of documentary information (e.g. Butzer and Butzer, 1997. The climatic information within the various archival and documentary sources can generally be divided into a number of categories. The first includes direct, dated descriptions and accounts of catastrophic, extreme or damaging, and hence noteworthy climate events such as hurricanes, frosts, droughts or floods. The second includes general anecdotal observations of contemporary climatic conditions, such as the early or late arrival of the summer rainy season, unusually dry or wet conditions and the implications this had particularly for agricultural communities. The third comprises indirect evidence, where the reporting of a climate event per se was not the main purpose of the document. This category might include references to harvest gains or losses, crop blights, disputes over changes in availability of and access to water sources and descriptions of the physical impact of climate change on the landscape as recorded in written descriptions, maps, drawings (pinturas) or photographs.

During the Colonial period a vast quantity of documents from the various levels of the Spanish administration, accumulated in local, regional and national Archives. Documents were also preserved in Spain itself in the Archivo de Indias in Seville and other Spanish archives. The single most important archive in Mexico is the Archivo General de la Nación (AGN) in Mexico City, home to by far 